\title{
Ayushmaan Bharat: Boon for Medical Disorders and Bane for Mental Illness in India
}

\section{Priya Ranjan Avinash ${ }^{1 *}$ and Rohit Gondwal ${ }^{2}$}

${ }^{1}$ Associate Professor, Department of Psychiatry, Himalayan Institute of Medical

Sciences, Swami Rama Himalayan University, Dehradun, India

${ }^{2} J u n i o r$ Resident, Department of Psychiatry, Himalayan Institute of Medical Sciences,

Swami Rama Himalayan University, Dehradun, India

*Corresponding Author: Priya Ranjan Avinash, Associate Professor, Department

of Psychiatry, Himalayan Institute of Medical Sciences, Swami Rama Himalayan

University, Dehradun, India.
Received: December 06, 2020

Published: December 22, 2020

(C) All rights are reserved by Priya Ranjan

Avinash and Rohit Gondwal.

\begin{abstract}
Ayushman Bharat a pan India health insurance scheme was launched in 2018. Since its inception, it has been lauded by all. However it has a huge lacunae as far as Mental health care is concerned. The policy makers seem to have forgotten that a huge chunk of mental health care is provided by private health care facilities and ironically private healthcare machineries have been kept out of the purview of this scheme. mental healthcare burden is huge and often born exclusively by caregivers which lead to delayed and inadequate healthcare. We propose the inclusion of private healthcare in the Ayushman Bharat Scheme.
\end{abstract}

Keywords: Ayushman Bharat; Mental Health Care; DALY; MHCA2017

In 1954, First Director-General of WHO, Dr Brock Chisholm, said "without mental health there can be no true physical health" [1]. Currently, mental wellness has become one of the major causes of disability in the world and it's on a rising curve. In India, in terms of daily adjusted life years (DALY) the total burden of mental illness has increased from 2.5\% in 1990 to $4.7 \%$ in 2017 [2]. Ironically the awareness regarding mental illnesses and treatment seeking as well as health care resources related to mental illness is in a grim state [3].

According to a survey conducted in 2019 there are around 9000 psychiatrists in India and 700 psychiatrists graduate each year. In figures, India has 0.75 psychiatrists per 100,000 population, while the expected number is 3 per 100,000 by WHO [4]. To complicate the matter further, it is to be noted with a pinch of salt, that certain states of India has even lesser number of psychiatrist than the national average [5].
In 1982, in India, national mental health program(NMHP) was brought into action that aimed of ensuring the availability and accessibility of minimum mental health care for all, especially for underprivileged and vulnerable population. It also aimed of increasing mental health knowledge and social growth by promoting community participation [6].

Most recently, the Mental Health Care Act 2017 was brought in India which specified that "Every person with mental illness shall be treated as equal to persons with physical illness in the provisions of all health care". Also according to section 21 of this act "Every insurer needs to make provisions for mental illness on the same basis as is available for treatment of physical illness". The effect of this was that that insurance companies which are under Insurance Regulatory and Development Authority of India were advised to add mental illness in their medical insurance schemes [7]. 
Recently the government has put up a new strategy for healthcare insurance known as Ayushmaan Bharat, which is a milestone in schemes of Government of India. This offers up to 5 lakhs insurance cover for treatment of any medical conditions. For the first time, it has included a cover for mental disorders as well, which may play an important role in reducing treatment gaps in treatment of mental illnesses. It has 17 packages for mental health disorders, which also includes psychoactive substance use disorders. It covers various biological treatment modalities such as electro convulsive therapy (ECT), repetitive trans-magnetic stimulation (TMS) and most of the blood investigations needed for management. There is also a provision of ensuring availability of certain psychotropic medications at low cost in government hospital pharmacy and Jan Ayushadhi Kendra. According to health package 2.0 published in December 2019 by the National Health Authority, it was urged that mental health packages should be reserved only for Public Hospitals, not for private medical colleges and hospitals. This is a major drawback leading to wide gaps in treatment of mental illnesses [8].

The National Income Data of India indicates that monthly percapita family income in India is INR 11,254 [9]. According to a study, on chronic and severe mental illnesses in a tertiary care hospital, the average monthly per-capita income of sample population was INR 1680. It reported that the average monthly cost of treatment in patients with life-threatening mental illness was INR 770 [10]. In this contrast, another study in 2018 which reports about monthly expenses (includes cost of consultation, medical drugs, medical tests, convenience charges, etc.) on treatment of chronic mental illness patient averaged the expenditure to INR 1,600 [11]. There are few more studies which reports that the cost of homecare ranges from INR 700/month to INR 2,250/month for varieties of mental illness in India [12-14]. Half of them are reported to be from medicines and medical investigations [15]. Another of survey reported that indirect costs $(63 \%)$ take a major proportion of total treatment expenditure for schizophrenia [13].

The present state of India is very disappointing as the number of cases of mental illnesses are increasing swiftly leading to increase in the burden on our limited healthcare resources. The data of Indian daily wage show that average Indian wage is around 356.30 INR according to Government of India. Sadly patient and family visiting psychiatry OPD go through overburden of household care of mental illness, which are beyond the means of an Indian daily wage worker. Sometimes it is also discovered that the only income provider in the family is mentally ill, which leads to snatching of all sources of income from the family. Subsidized care provided by government hospitals are far and few and many times not accessible to such impoverished persons with mental illness. If they are taken to private hospitals, the expenses are a big deterrent. Often such patients are not treated properly due to financial reasons and are taken to faith-healers. This is a major cause of treatment gap in India.

Similarly in Japan there were less psychiatric patients seeking care in government healthcare facilities due to the stigma attached to the malady. For this there government decided to introduce a financial inducement to local private psychiatric clinics by increasing day care services and consultation [16]. This establishes the fact that inclusion of private healthcare in the mainstream, leads to increase help seeking and reduction of treatment gap.

In conclusion, the government of India should also rope in private sector hospitals for treatment of mental illnesses. This can be done only by inclusion of psychiatry treatment and care in private as well as government facilities in the Ayushman Bharat Yojna. This should definitely improve the present state of treatment gaps in mental illnesses.

\section{Bibliography}

1. Srivastava K., et al. "Mental health awareness: The Indian scenario". Industrial Psychiatry Journal 25.2 (2016): 131.

2. Sagar R., et al. "The burden of mental disorders across the states of India: the Global Burden of Disease Study 19902017". The Lancet Psychiatry 7.2 (2020): 148-161.

3. Prince M., et al. "No health without mental health". Lancet 370.9590 (2007): 859-877.

4. WHO | Mental Health Atlas 2014. WHO (2019).

5. Kabir Garg C and Naveen Kumar PSC. "Number of psychiatrists in India: Baby steps forward, but a long way to go". Indian Journal of Psychiatry 61.1 (2017): 104-105.

6. National Mental Health Programme (NMHP): National Health Mission (2020).

7. $\quad$ Singh 0. "Insurance for mental illness: Government schemes must show the way Vol. 61, Indian Journal of Psychiatry". Wolters Kluwer Medknow Publications (2019): 113-114. 
8. The Ayushman Bharat Scheme of Government of India (2020).

9. Per capita income: India's per capita income grows by $8.6 \%$ to Rs 1.13 lakh in FY18 | India Business News - Times of India (2020).

10. Siddharth Sarkar., et al. "Cost-of-treatment of clinically stable severe mental lilnesses in India". Indian Journal of Social Psychiatry 33.3 (2017): 262-268.

11. Chavan BS., et al. "Prevalence of mental disorders in Punjab: Findings from National Mental Health Survey". Indian Journal of Psychiatry. Medknow Publications 60.1 (2018): 121-126.

12. Chisholm D., et al. "Integration of mental health care into primary care". British Journal of Psychiatry 176.6 (2000): 581588.

13. Grover S., et al. "Cost of care of schizophrenia: a study of Indian out-patient attenders". Acta Psychiatrica Scandinavica 112.1 (2005): 54-63.

14. Gautham MS., et al. "Prevalence, socio-demographic correlates and treatment gap of mental morbidity". International Journal of Social Psychiatry 66.4 (2020): 361-372.

15. Engelgau MM., et al. "The Economic impact of Non-communicable Diseases on households in India". Globalization and Health 8 (2012): 9.

16. Sasaki H. "The role of private sector psychiatry in the Japanese mental health system". International Journal of Mental Health 41.2 (2012): 61-71.

\section{Assets from publication with us}

- Prompt Acknowledgement after receiving the article

- Thorough Double blinded peer review

- Rapid Publication

- Issue of Publication Certificate

- High visibility of your Published work

Website: www.actascientific.com/ Submit Article: www.actascientific.com/submission.php Email us: editor@actascientific.com

Contact us: +919182824667 